\title{
ACCESSIBILITY OF THE MINOR GROOVE OF DNA IN CHROMATIN TO THE BINDING OF ANTIBIOTICS NETROPSIN AND DISTAMYCIN A
}

\author{
A. F. MELNIKOVA, A. S. ZASEDATELEV, A. M. KOLCHINSKY, G. V. GURSKY, \\ A. L. ZHUZE, S. L. GROCHOVSKY, and A. D. MIRZABEKOV \\ Institute of Molecular Biology, Academy of Sciences of the U.S.S.R., Moscow, U.S.S.R.
}

(Received 24 March, 1975)

\begin{abstract}
The interaction of the antibiotics distamycin A, distamycin analogue and netropsin with chromatin of calf thymus has been studied by circular dichroism measurements and by gel filtration. The minor groove of DNA in chromatin is accessible by $83-89 \%$ to the binding of these antibiotics as compared with that of free DNA. The present results combined with our data on the methylation of chromatin with dimethylsulphate [3] strongly suggest that the minor groove of DNA in chromatin is not occupied by chromatin proteins.
\end{abstract}

Abbreviations. DM - distamycin A; $\mathrm{DM}_{2}$ - analogue of distamycin; $\mathrm{Nt}$ - netropsin; CD spectra - circular dichroism spectra.

\section{INTRODUCTION}

Detailed information on the structure of chromatin is required in order to understand the mechanisms of functioning of the eukaryotic genome. Double helical DNA in chromatin is present in the $\mathrm{B}$ configuration or in the very similar $\mathrm{C}$ configuration in a complex with histones and non-histone chromosomal proteins (for ref. see [1]). At present there are only scarce experimental data on whether the binding of chromatin proteins occurs in the minor and/or the major groove or over the grooves of DNA. Simpson [2] has suggested that the minor groove of DNA is not occupied by chromatin proteins since a reporter molecule, which is believed to interact with the minor groove, is bound to the same extent by chromatin as by native DNA. Using methylation with dimethylsulphate we $[3,4]$ have found recently that the sites of methylation within the minor groove are equally accessible to the reagent in free DNA as in chromatin, but within the major groove they are more protected in chromatin than in DNA. We conclude therefore that histones occupy the major groove partly but not the minor groove of DNA in nuclei.

The studies of methylation with dimethylsulphate of the complexes of DNA with distamycin $\mathrm{A}$ (DM) and netropsin (Nt) [5] combined with data on the binding of these antibiotics with natural and synthetic polydeoxyribonucleotides [6-10] as well as the recently proposed model of their complex $[8,9]$ indicate that DM and $\mathrm{Nt}$ interact with DNA along the minor groove and 
do not intercalate and probably from hydrogen bonds with the $\mathrm{C}=\mathrm{O}$ groups of thymine or the $\mathrm{N} 3$ atom of adenine in the minor groove.

The present studies show that the extent and the mode of binding of DM and Nt to the minor groove of both free DNA and chromatin DNA are similar.

\section{MATERIALS AND METHODS}

Native DNA from calf thymus $\left(E_{258 \mathrm{~nm}}=6650 \mathrm{~cm}^{-1} \mathrm{M}^{-1}\right.$ in DNA phosphate) was prepared as described previously [11]. Chromatin from calf thymus was prepared according to Marushige and Bonner [12]. The thymus was homogenized in $0.075 \mathrm{M} \mathrm{NaCl}, 0.024 \mathrm{M}$ EDTA, pH 8.0, and chromatin was purified by centrifugation through $1.7 \mathrm{M}$ sucrose, $0.01 \mathrm{M}$ sodium cacodylate, $\mathrm{pH}$ 7.0. To prepare soluble chromatin the latter was dialyzed against $0.01 \mathrm{M}$ sodium cacodylate, $\mathrm{pH} 7.0$, sonicated for $5 \mathrm{~min}$ at $22 \mathrm{kc} \mathrm{s}^{-1}$ in ten $30-\mathrm{s}$ bursts $0.6 \mathrm{~A}$ in a USDH-1 sonicator and then centrifuged at $10000 \times \mathrm{g}$ for $30 \mathrm{~min}$. The DNA concentration in chromatin was determined by the diphenylamine method [13], using the prepared calf thymus DNA as a standard; it gave $E_{258 \mathrm{~nm}}=7300 \pm 100 \mathrm{~cm}^{-1} \mathrm{M}^{-1}$ for chromatin.

$\mathrm{Nt}\left(E_{297 \mathrm{~nm}}=21500 \mathrm{~cm}^{-1} \mathrm{M}^{-1}\right)$ was a gift from Dr. Ch. Zimmer. DM $\left(E_{303 \mathrm{~nm}}=30000\right)$ and the shorter analogue of DM $\left(\mathrm{DM}_{2}\right)$ containing two $\mathrm{N}$-methylpyrrole residues $\left(E_{238 \mathrm{~nm}}=21500\right)$ as in Nt instead of three as in DM were synthesized by us (S.L.G. and A.L.Z.).

The binding of $\mathrm{Nt}, \mathrm{DM}$ and $\mathrm{DM}_{2}$ to DNA chromatin was determined quantitatively by measurement of the magnitude of CD spectra at 305,320 , and $315 \mathrm{~nm}$, respectively $[5,8,10]$. The solutions of DNA and chromatin at a concentration of $2.8 \times 10^{-5} \mathrm{M}$ in DNA phosphate in $0.01 \mathrm{M}$ sodium cacodylate buffer, $\mathrm{pH} 7.0$ were titrated directly in $2-\mathrm{cm}$ path length cell with solutions of the antibiotics $\left(5 \times 10^{-4} \mathrm{M}\right)$ in the same buffer at $20^{\circ} \mathrm{C}$. The molar ratio of the antibiotic added to a base pair is reported as $r=2 C / P$, where $C$ is the concentration of the antibiotic (M), and $P$ is the concentration of DNA phosphate (M). CD spectra were recorded with a RousselJouan II dichrograph. $2 \triangle O . D . / P$ - the measured dichroism expressed per $1 \mathrm{~cm}$ path length $(\triangle O . D$.$) per mole of DNA base paris (P / 2)$.

\section{RESULTS}

Figure 1 shows the CD spectra of DNA, chromatin, their complexes with $\mathrm{Nt}$ and difference CD spectra obtained by subtracting the spectra of DNA and chromatin from the spectra of the complexes. The difference CD spectra of DNA and chromatin show remarkable similarity, and irrespective of some quantitative differences, this similarity of the two spectra suggests similar modes of interaction of $\mathrm{Nt}$ with DNA in the two situations $[8,10]$. Comparable results were obtained with $\mathrm{DM}$ and $\mathrm{DM}_{2}$.

$\mathrm{CD}$ measurements were used to determine the saturation levels of binding of $\mathrm{DM}, \mathrm{DM}_{2}$ and $\mathrm{Nt}$ to DNA and chromatin. Figure 2 shows data for the titration of DNA and chromatin with the antibiotics. The CD magnitude at 320,315 and $305 \mathrm{~nm}$ were taken as a measure of the extent of binding of $\mathrm{DM}, \mathrm{DM}_{2}$ and $\mathrm{Nt}$, respectively, since the $\mathrm{CD}$ magnitude was found to be proportional to the amount of the antibiotics bound to DNA [5,8,10]. In Figure 2 the CD magnitude was plotted against the amount of the antibiotic added for a base pair $(r)$. The saturation level of binding, $r_{\max }$, can be determined by the intersection point of the asymptotic lines shown in Figure 2 [8]. 


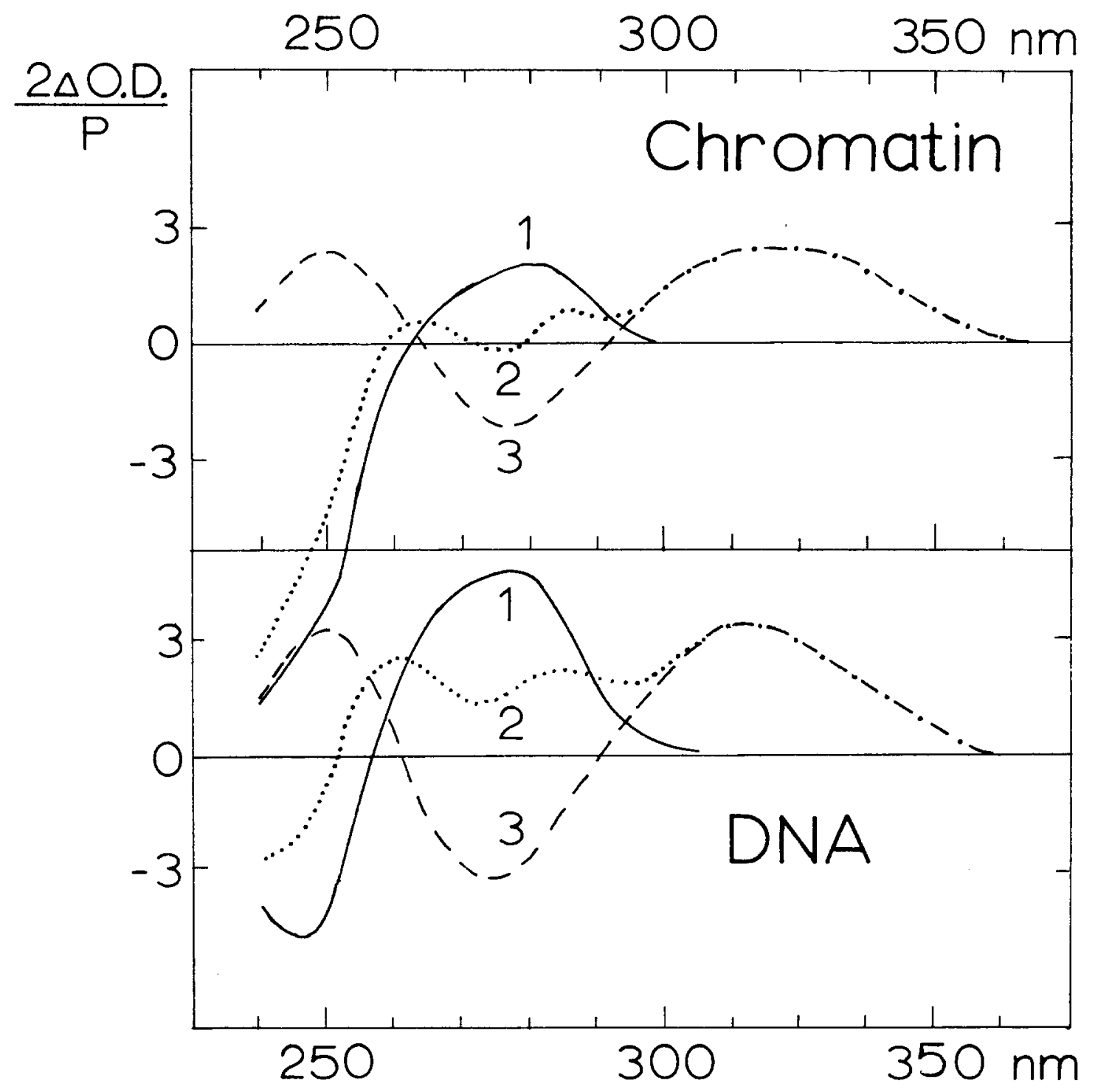

Fig. 1. Cd spectra of DNA and chromatin (1), of their complexes with Nt (2) and difference CD spectra (3) obtained by subtracting the spectra of chromatin or DNA from the spectra of the complexes. The amount of $\mathrm{Nt}$ in the complexes was $r=0.08$. 


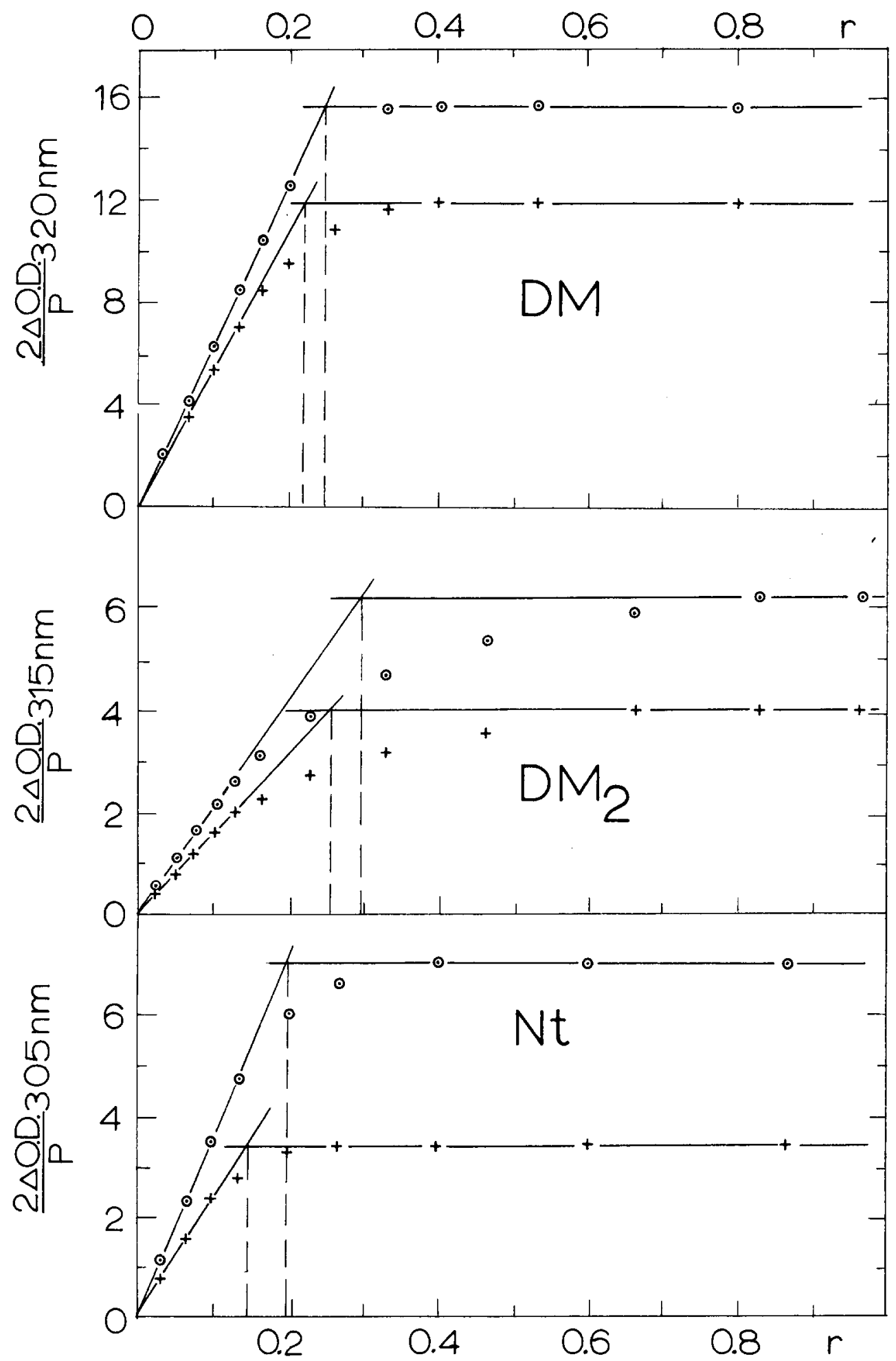

Fig. 2. Plot of the CD magnitude of the complexes of the $\mathrm{DM}, \mathrm{DM}_{2}$ and $\mathrm{Nt}$ with $\mathrm{DNA}(-\odot-\odot-)$ ) or with chromatin $(+-+-+-)$ versus the amount of the antibiotics added $(r)$. 
The relative accessibility $(\alpha)$ to the antibiotics of the minor groove in chromatin-DNA compared to that of DNA alone, namely, the ratio of the amount of antibiotic binding to chromatin to the amount of antibiotic binding to DNA is given by the following expression:

$\alpha=\frac{\left(r_{\max }\right) \text { chromatin }}{\left(r_{\max }\right) \text { DNA }} \times 100(\%)$.

The values of $\alpha$ presented in Table I show that $\mathrm{DM}, \mathrm{DM}_{2}$ and $\mathrm{Nt}$ are bound to DNA in chromatin by 89,87 and $83 \%$, respectively, as compared with the binding of the antibiotics to free DNA.

TABLE I: The relative accessibility $(\alpha)$ of the minor groove of DNA in chromatin against that of the same DNA alone to the binding of $\mathrm{DM}, \mathrm{DM}_{2}$ and $\mathrm{Nt}$

\begin{tabular}{lc}
\hline Antibiotic & $\alpha(\%)$ \\
\hline Dystamycin A & $89 \pm 2$ \\
Analogue of dystamycin A(DM 2$)$ & $87 \pm 3$ \\
Netropsin & $83 \pm 3$ \\
\hline
\end{tabular}

The initial slope of the titrating curves is less in the case of the antibiotic binding to chromatin than the slope in the case of their binding to DNA. The altered conformational state of DNA in chromatin may account for this yet unknown mechanism which could induce a reduction in the magnitude of the CD spectra upon antibiotic binding to chromatin in comparison with the magnitude upon its binding to free DNA.

High accessibility of the minor groove of DNA in chromatin to antibiotic binding needs further evaluation, namely, whether the antibiotics bind to chromatin as such, or, alternatively, whether the antibiotics bind to DNA with concommitant dissociation of the proteins of the chromatin. We did not observe any noticeable removal of proteins from chromatin upon DM binding. At least $99 \%$ of the proteins remain attached to DNA during gel filtration fo the mixture of chromatin with 1.5 fold excess of DM over the amount of DM which saturates chromatin (Figure 3). Less than $1 \%$ of chromatin proteins could be found in the fractions between $15-25 \mathrm{ml}$ where serum albumin and pancreatic ribonuclease were eluted and where proteins detached from chromatin would probably appear.

Since the binding (association) constant for DM of DNA is rather high than $10^{8} \mathrm{M}^{-1}$ ) [10] there was no dissociation of the antibiotic from its complex with chromatin during gel filtration. The measurement of DM concentration at $320, \mathrm{~nm}$ showed that the fraction eluted between 5-12 ml contains chromatin in a complex with a saturating amount of DM in the ratio of $0.12 \mathrm{M}$ of DM per mole of DNA phosphates [5].The measurement of DM concentration was carried out at $320 \mathrm{~nm}\left(E_{320 \mathrm{~nm}}=25500 \mathrm{~cm}^{-1} \mathrm{M}^{-1}\right)$ where the spectra of free DM and DM bound to DNA show an isosbestic point and chromatin has no absorbance. 


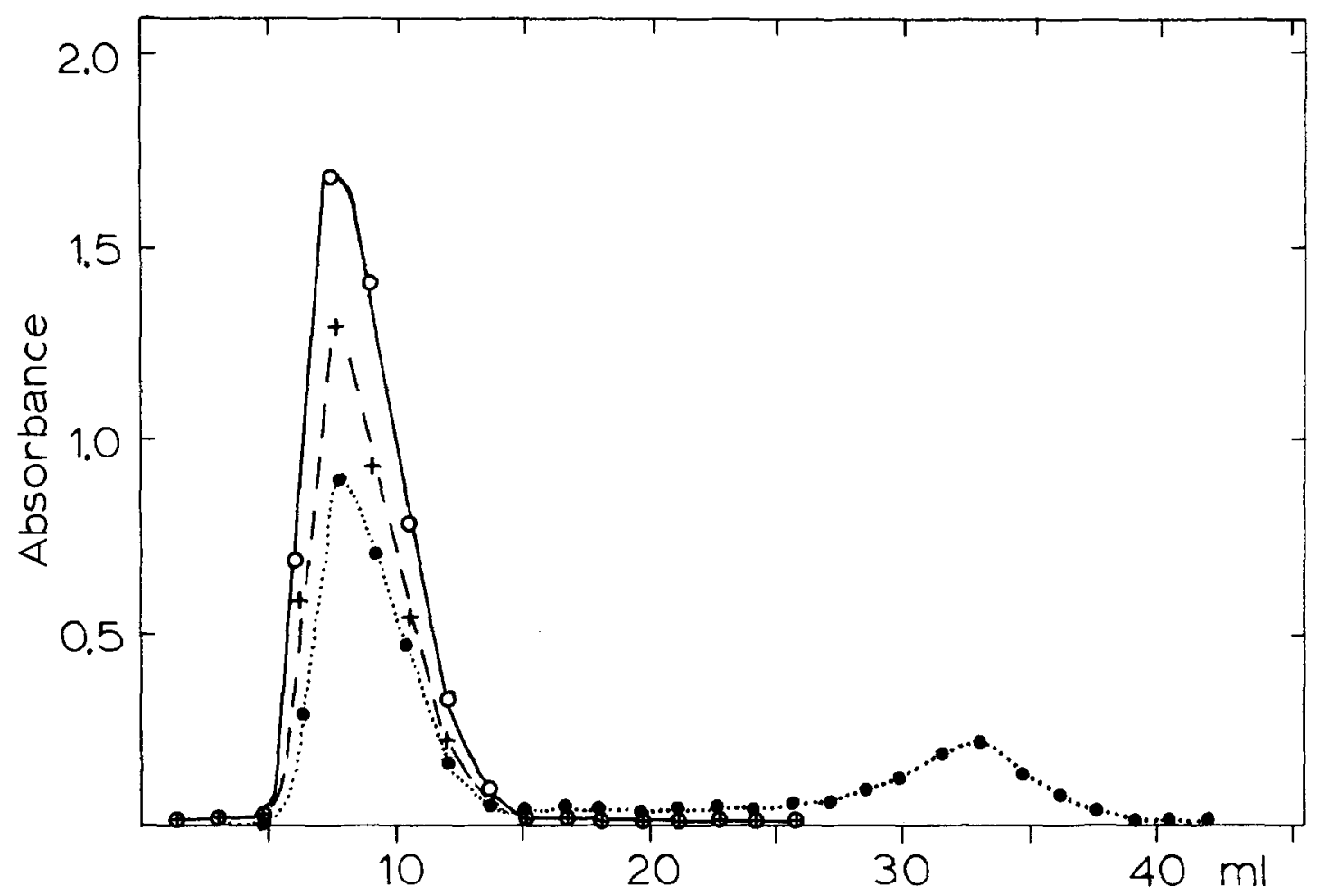

Fig. 3. Gel filtration of the complexes of chromatin with DM. A $1.0 \times 28 \mathrm{~cm}$ column of Sepharose $4 B$ equilibrated with $0.01 \mathrm{M}$ sodium cacodylate buffer, $\mathrm{pH} 7.0$, was employed. A 1-ml sample of chromatin, $1.4 \times 10^{-3} \mathrm{M}$ in DNA phosphate, and DM, $0.25 \times 10^{-3} \mathrm{M}$, was applied to the column in the equilibrating buffer, and eluted with the same buffer. The presence of DM was measured by absorbance at $320 \mathrm{~nm}$ (.......... The DNA content was determined by absorbance at $260 \mathrm{~nm}(-0-0-)$. The protein content was determined by this absorbance at $230 \mathrm{~nm}\left(+-+-+_{-}\right)$. The absorbance of DM at 260 and $230 \mathrm{~nm}$ was subtracted to measure the DNA or protein content, respectively (for DM $A_{320 \mathrm{~nm}} / A_{260 \mathrm{~nm}}=1.40$, $\left.A_{320 \mathrm{~mm} / A_{230 \mathrm{~nm}}}=1.05\right)$.

\section{DISCUSSION}

DNA in chromatin is highly accessible for the binding of DM, $\mathrm{DM}_{2}$ and $\mathrm{Nt}$ (by 89,87 and $83 \%$, respectively) within the minor groove (Tabel I) as compared to the antibiotic binding to the same DNA in the free state. According to our recent report [14] Actinomycin D which also occupies the minor DNA groove $[5,15,16]$ nevertheless binds to chromatin only about half as much as to free DNA. This discrepancy may be due to the fact that Actinomycin D molecule causes unwinding of DNA by $26^{\circ}$ upon binding [17]. Such distortion of the DNA structure and subsequent Actinomycin binding to chromatin can be well opposed by histones even if histones do not occupy the minor groove. On the other hand, DM and $\mathrm{Nt}$ do not change the angle of twisting of the DNA double helix, do not intercalate and do not appear to distort the B or C configuration of DNA upon binding [6-10]. It is therefore apparent that these antibiotics possess characteristics quite appropriate to test the state of the minor groove of DNA in chromatin.

A small protection 11-17\% of the minor DNA groove in chromatin against the antibiotic binding might be due to the partial occupation of this groove by chromatin proteins. However, another explanation seems to be more adequate. Electrostatic interactions between phosphate 
groups of DNA and positive charged propionamidino and guanidino groups of these antibiotics are important for complex formation $[9,18]$. It is shown by different methods that about $50 \%$ of phosphate groups of DNA in chromatin are shielded $[19,20]$, and this might partly prevent electrostatic interaction of DNA and the antibiotics and cause a decrease in the antibiotics binding to chromatin. Thus, $\mathrm{DM}_{2}^{1+}$ with one positive charge in the molecule differs from $\mathrm{Nt}^{2+}$ only by a lack of a positively charged guanidino group and therefore $\mathrm{DM}_{2}$ seems to be less sensitive to the screening of DNA phosphates in chromatin. In agreement with this, the amount of the sites on chromatin DNA inaccessible for binding is markedly less in the case of $\mathrm{DM}_{2}$ (13\%) than in the case of Nt (17\%, Table I) in spite of the fact that Nt binds to DNA more tightly than $\mathrm{DM}_{2}$ [5].

The difference CD spectra of the complexes of Nt with DNA and chromatin are similar (Figure 1) and this suggests the absence of significant conformational changes in the course of the antibiotic binding as well as similar modes of antibiotic interaction with DNA and chromatin. Likewise, DM in the complex with chromatin does not seem to displace chromatin proteins (Figure 3$)$. Therefore the high (83-89\%) accessibility of the minor groove of DNA in chromatin for binding of $\mathrm{DM}, \mathrm{DM}_{2}$ and $\mathrm{Nt}$ suggests that this groove is free of chromatin proteins at least by $90 \%$ and perhaps even more.

In the present experiments we could not exclude the possibility that, while these antibiotics do not compete with chromatin proteins for the binding to ribose-phosphate backbone, nevertheless the antibiotics could drive histones out of the minor groove. We may expect that this is not the case in methylation with dimethylsulphate of the minor groove of DNA in chromatin. The extent [3] and the initial rate of methylation (manuscript in preparation) of the N3 atom of adenine inside the minor groove is equal both in the case of the modification of DNA and chromatin $[3,18]$. Since dimethylsulphate seems to have a low association constant for binding to DNA one may conclude that it does not displace the chromatin proteins from the minor groove of DNA before the reaction takes place.

The high accessibility of the minor groove of DNA in chromatin interaction with such different molecules as the antibiotics $\mathrm{DM}, \mathrm{DM}_{2}$ and $\mathrm{Nt}$ or dimethylsulphate strongly suggests that the chromatin proteins virtually do not occupy the minor groove of DNA. The protection of the major DNA groove by histones against methylation with dimethylsulphate $[3,4]$ suggests that histones are partly localized within the major groove.

\section{REFERENCES}

1. Simpson, R. T., Adv. in Enzymology 38, 41 (1973).

2. Simpson, R. T., Biochemistry 9, 4814 (1970).

3. Mirzabekov, A. D. and Melnikova, A. F., Mol. Biol. Reports 1, 385 (1974).

4. Mirzabekov, A. D. and Kolchinsky, A. M., Mol. Biol. Reports 1, 379 (1974).

5. Kolchinsky, A. M., Mirzabekov, A. D., Zasedatelev, A. S., Gursky, G. V., Grochovsky, S. L., Zhuse, A. L., and Gottikh, B. P., Mol. Biol. (U.S.S.R.) 9, 19 (1975).

6. Krey, A. K., Alison, R. G., and Hahn, F. E., FEBS Letters 29, 58 (1973).

7. Luck, G., Triebel, H., Waring, M. J., and Zimmer, Ch., Nucleic Acids Res. 1, 503 (1974).

8. Zasedatelev, A. S., Gursky, G. V., Zimmer, Ch., and Thrum, H., Mol. Biol. Reports 1, 337 (1974). 
9. Wartell, R. M., Larson, J. E., and Wells, R. D., J. Biol. Chem. 249, 6719 (1974).

10. Zasedatelev, A. S., Gursky, G. V., Zimmer, Ch., and Thrum, H., Biochim. Biophys. Acta (submitted for publication).

11. Dahmus, M. E. and McConnell, D. J., Biochemistry 8, 1524 (1969).

12. Marushige, J., and Bonner, J., J. Mol. Biol. 15, 160 (1966).

13. Burton, K., Biochem. J. 62, 315 (1956).

14. Gursky, G. V., Zasedatelev, A. S., Minyat, E. E., Ilyin, Yu. V., Georgiev, G. P., and Volkenstein, M. V., Mol. Biol. (U.S.S.R.) 8, 18 (1974).

15. Cerami, A., Reich, E., Ward, D. C., and Goldberg, I. H.,Proc. Nat. Acad. Sci. U.S. 57, 1036 (1967).

16. Sobell, H. M., Jain, S. C., Sakore, T. D., and Nordman, C. E., Nature, New Biol. 231, 200 (1971).

17. Wang, J. C., J. Mol. Biol. 89, 783 (1974).

18. Zimmer, Ch., Luck, G., Thrum, H., and Pitra, C., Eur. J. Biochem. 26, 81 (1972).

19. Itzhaki, R. F., Biochem. J. 122, 583 (1971).

20. Clark, R. J. and Felsenfelf, G., Biochemistry 13, 3622 (1974). 